\title{
Patient outcomes following surgical management of thyroid nodules classified as Bethesda category III (AUS/FLUS)
}

\author{
Francesk Mulita ${ }^{\circledR 1}$, Maria-Kerasia Plachouri ${ }^{\circledR 2}$, Elias Liolis ${ }^{(1)}{ }^{3}$, Michail Vailas ${ }^{(1)}$, \\ Konstantinos Panagopoulos (101, Ioannis Maroulis (101 \\ ${ }^{1}$ Department of Surgery, General University Hospital of Patras, Patras, Greece \\ ${ }^{2}$ Dermatology Department, General University Hospital of Patras, Patras, Greece \\ ${ }^{3}$ Division of Oncology, Department of Medicine, General University Hospital of Patras, Patras, Greece
}

\begin{abstract}
Introduction: The Bethesda classification system for reporting thyroid cytopathology is the standard for interpreting fine needle aspirate (FNA). Because of its heterogeneity and inconsistent reporting, atypia of undetermined significance or follicular lesion of undetermined significance (AUS/FLUS), known as Bethesda category III, is the most controversial category. Thyroid nodules that fall within Bethesda categories III-IV have an overall risk of malignancy of between 15 and $40 \%$. The aim of this study was to determine the malignancy rate in Bethesda III nodules.

Material and methods: A retrospective study was performed for 1166 patients who underwent thyroid surgery for multinodular goitre (MNG) or solitary nodular goitre (SNG) in our institution between June 2010 and May 2020. Data retrieved included demographic characteristics of the patients, FNB cytology, thyroid function test results, type of thyroidectomy, and final histology results.

Results: During the study period, 29.5\% (344/1166) of patients with an FNA categorized as AUS/FLUS underwent thyroid surgery. Of these 344 patients, 190 were diagnosed with MNG and 154 with SNG. Incidental malignancy was found in 35 of 190 cases of MNG (18.42\%) and 31 of 154 cases of SNG (20.13\%). The most common malignant tumour type in either category was the follicular variant of papillary thyroid carcinoma.

Conclusions: The current study demonstrates that patients with a FNA categorized as AUS/FLUS may have a higher risk of malignancy than traditionally believed. Reconsideration may be necessary to guidelines that recommend observation or repeat FNA in this category of patients. (Endokrynol Pol 2021; 72 (2): 143-144)
\end{abstract}

Key words: thyroid nodule; thyroid cancer; Bethesda classification

\section{Introduction}

The incidence of thyroid cancer has increased dramatically in the last few decades, and it is now the fastest growing cancer in females, with papillary thyroid carcinoma (PTC) accounting for the majority of cases [1]. However, thyroid lesions are often found on the thyroid gland, and the majority of these are not malignancies. After an initial ultrasound (US), the next step in assessing the risk of cancer of a thyroid lesion is fine needle aspiration (FNA) [2]. The result of the biopsy can fall within one of six categories as defined by the Bethesda system for reporting FNA cytopathology results: I (non-diagnostic or unsatisfactory), II (benign), III (atypia of undetermined significance [AUS] or follicular lesion of undetermined significance [FUS]), IV (follicular neoplasm or suspicious for a follicular neoplasm), $\mathrm{V}$ (suspicious for malignancy), and VI (malignant) [3]. Because of its heterogeneity and inconsistent reporting, (AUS/FLUS), also known as Bethesda category III, is the most controversial category [4]. The aim of this study was to determine the malignancy rate in Bethesda III nodules in patients undergoing thyroidectomy for multinodular goitre (MNG) or solitary nodular goitre (SNG) in our institution.

\section{Material and methods}

Between June 2010 and May 2020, 344 out of 1166 patients who underwent thyroid surgery for multinodular goitre (MNG) or solitary nodular goitre (SNG) in our institution had a FNA categorized as AUS/FLUS and were considered for this retrospective study. Informed consent or approval by the local ethics committee was not obtained due to the observational nature of the study. Data were collected from medical and operating theatre records as well as from the hospital-coded database. Statistical analyses were done using SPSS for Windows 8.0. Student's t-test for normally distributed variables, Mann-Whitney U test for skewed variables, and chi-square test and Fisher's exact tests for comparison of results between groups. A $p$ value $<0.05$ was considered statistically significant.

\section{Results}

During the study period, $29.5 \%$ (344/1166) of patients with a FNA categorized as AUS/FLUS underwent thy- 
roid surgery in our institution. Of these 344 patients, 190 were diagnosed with MNG and 154 with SNG. Total thyroidectomy was performed in $15.1 \%$ (52/344) of the nodules with AUS/FLUS, subtotal thyroidectomy in $81.1 \%(279 / 344)$ of cases, and thyroid lobectomy in $3.8 \%(13 / 344)$ of these patients. The demographic data of the patients with MNG and SNG are presented in Table 1 . There were more female patients than male in both the MNG and SNG groups. The mean age of patients with MNG at the time of surgery was $48.6 \pm 11.18$ years, with no significant difference compared with the patients with SNG, at $47.9 \pm 12.35$ years. In addition, there was no significant difference regarding operation time, hospital stay, and rate of malignancy between the two groups. Incidental malignancy was found in 35 of 190 cases of MNG (18.42\%) and in 31 of 154 cases of SNG $(20.13 \%)$. The most common malignant tumour type in either category was the follicular variant of papillary thyroid carcinoma. There was no significant difference regarding histological subtypes of all other malignant tumours between the MNG and SNG groups.

\section{Discussion}

The results of our study demonstrate that the rate of malignancy is $18.1 \%$ for AUS/FLUS patients with MNG and $20.1 \%$ for those with SNG, and the most common subtype is follicular variant of papillary thyroid carcinoma (PTC). According to the literature, thyroid

Table 1. Number of cases, gender, age, hospitalization, duration of surgery, and histological outcomes for the undetermined significance or follicular lesion of undetermined significance (AUS/FLUS) patients with multinodular goitre (MNG) and solitary nodular goitre (SNG). Values are presented as mean \pm standard deviation $(S D)$ with percentage in parentheses

\begin{tabular}{|c|c|c|c|}
\hline Variable & MNG & SNG & $\mathbf{p}$ \\
\hline $\begin{array}{l}\text { Number of patients } \\
(\mathrm{n}=344)\end{array}$ & $190(55)$ & $154(45)$ & \\
\hline $\begin{array}{l}\text { Males/Females } \\
(67 / 277)\end{array}$ & $36 / 154$ & $31 / 123$ & $>0.05^{*}$ \\
\hline $\begin{array}{l}\text { Mean age }( \pm \mathrm{SD}) \\
{[\mathrm{yrs}]}\end{array}$ & $48.6 \pm 11.18$ & $47.9 \pm 12.35$ & $>0.05$ \\
\hline $\begin{array}{l}\text { Hospitalization } \\
( \pm \mathrm{SD})[\mathrm{d}]\end{array}$ & $4.3 \pm 2.7$ & $4.1 \pm 2.9$ & $>0.05$ \\
\hline $\begin{array}{l}\text { Malignancies } \\
(n=66)\end{array}$ & $35(18.4)$ & $31(20.1)$ & $>0.05$ \\
\hline $\begin{array}{l}\text { Mean operative } \\
( \pm \mathrm{SD}) \text { time }[\mathrm{min}]\end{array}$ & $103.1 \pm 59.1$ & $101.7 \pm 47.4$ & $>0.05$ \\
\hline
\end{tabular}

${ }^{*}$ statistically significant $(p<0.05)$ nodules that fall within Bethesda categories III and IV have an overall risk of malignancy of between 15 and $40 \%$. If Bethesda III or IV lesions are found to be malignant, the most common histological subtype is the follicular variant of papillary thyroid carcinoma. This variant is generally less aggressive than classic papillary thyroid carcinoma. Furthermore, this subtype has been shown to have a lower risk of lymph node metastases, recurrence, and local extension, especially if it is encapsulated [3].

A retrospective analysis showed that ultrasonography (K-TIRADS 5) is the most influential independent predictor of malignancy in AUS/FLUS patients [5]. Another retrospective study showed that the rate of malignancy of 350 nodules with AUS/FLUS that went on to surgery was approximately $38 \%$. They found that the most common malignancy was PTC (86.8\%) [4].

Our study has several limitations because the patients were assessed retrospectively from a single centre. Our study indicates the need for a prospective randomized controlled trial of AUS/FLUS patients with MNG and SNG.

\section{Conclusions}

In conclusion, the current study demonstrates that patients with a FNA categorized as AUS/FLUS may have a higher risk of malignancy than traditionally believed. Reconsideration may be necessary to guidelines that recommend observation or repeat FNA in this category of patients.

\section{Funding}

The authors received no specific funding for this work.

\section{Conflict of interest}

None.

\section{References}

1. Kopczyński J, Suligowska A, Niemyska K, et al. The influence of the reclassification of NIFTP as an uncertain tumour on risk of malignancy for the diagnostic categories according to the Bethesda system for reporting thyroid cytopathology. Endokrynol Pol. 2019; 70(3): 232-236, doi: 10.5603/EP.a2019.0008, indexed in Pubmed: 30845342

2. Mulita F, Anjum F. Thyroid Adenoma [StatPearls]. StatPearlsPublishing, Treasure Island 2020.

3. Kleiman DA, Beninato T, Soni A, et al. Does bethesda category predict aggressive features in malignant thyroid nodules? Ann Surg Oncol. 2013; 20(11): 3484-3490, doi: 10.1245/s10434-013-3076-5, indexed in Pubmed: 23812773.

4. Ho AS, Sarti EE, Jain KS, et al. Malignancy rate in thyroid nodules classified as Bethesda category III (AUS/FLUS). Thyroid. 2014; 24(5): 832-839, doi: 10.1089/thy.2013.0317, indexed in Pubmed: 24341462.

5. Suh YJ, Choi YJu. Strategy to reduce unnecessary surgeries in thyroid nodules with cytology of Bethesda category III (AUS/FLUS): a retrospective analysis of 667 patients diagnosed by surgery. Endocrine. 2020; 69(3): 578-586, doi: 10.1007/s12020-020-02300-w, indexed in Pubmed: 32297204. 